\title{
Multiplexed kit based on Luminex technology and achievements in synthetic biology discriminates Zika, chikungunya, and dengue viruses in mosquitoes
}

Lyudmyla G. Glushakova', Barry W. Alto², Myong-Sang Kim', Daniel Hutter', Andrea Bradley', Kevin M. Bradley', Nathan D. Burkett-Cadena ${ }^{2}$ and Steven A. Benner ${ }^{1 *}$

\begin{abstract}
Background: The global expansion of dengue (DENV), chikungunya (CHIKV), and Zika viruses (ZIKV) is having a serious impact on public health. Because these arboviruses are transmitted by the same mosquito species and cocirculate in the same area, a sensitive diagnostic assay that detects them together, with discrimination, is needed.

Methods: We present here a diagnostics panel based on reverse transcription-PCR amplification of viral RNA and an XMap Luminex architecture involving direct hybridization of PCRamplicons and virus-specific probes. Two DNA innovations ("artificially expanded genetic information systems", AEGIS, and "self-avoiding molecular recognition systems", SAMRS) increase the hybridization sensitivity on Luminex microspheres and PCR specificity of the multiplex assay compared to the standard approach (standard nucleotides).

Results: The diagnostics panel detects, if they are present, these viruses with a resolution of 20 genome equivalents (DENV1), or 10 (DENV3-4, CHIKV) and 80 (DENV2, ZIKV) genome equivalents per assay. It identifies ZIKV, CHIKV and DENV RNAs in a single infected mosquito, in mosquito pools comprised of 5 to 50 individuals, and mosquito saliva (ZIKV, CHIKV, and DENV2). Infected mosquitoes and saliva were also collected on a cationic surface (Q-paper), which binds mosquito and viral nucleic acids electrostatically. All samples from infected mosquitoes displayed only target-specific signals; signals from non-infected samples were at background levels.
\end{abstract}

Conclusions: Our results provide an efficient and multiplex tool that may be used for surveillance of emerging mosquito-borne pathogens which aids targeted mosquito control in areas at high risk for transmission.

Keywords: Zika, Chikungunya, Dengue viruses, Reverse-transcription PCR, Luminex DHA, Cationic paper

\section{Background}

Dengue (DENV), chikungunya (CHIKV), and Zika (ZIKV) viruses are mosquito-borne pathogens that have caused numerous outbreaks in Southeast Asia and more recently undergone geographic expansion in the Americas, causing emerging and serious health problems in humans [1-5]. Although dengue is not new to the Americas, the emergence of CHIKV and ZIKV add to the burden of disease in this region of the world.

\footnotetext{
* Correspondence: manuscripts@firebirdbio.com

${ }^{1}$ Firebird Biomolecular Sciences LLC, 13709 Progress Blvd, Box 17, Alachua, FL 32615, USA

Full list of author information is available at the end of the article
}

Endemic to Africa, these arboviruses have rapidly expanded their original geographical range and reached North America and Europe through their exploitation of invasive mosquito vectors [6-8].

The sylvatic transmission cycle of DENV, CHIKV, and ZIKV involves non-human primates and arboreal Aedes mosquitoes [9-12]. Domestic container mosquitoes Ae. aegypti and Ae. albopictus are primarily responsible for transmission of these arboviruses to humans [13-15]. Sufficiently high viremia levels of these pathogens predisposes epidemics in human populations that are sustained by human-mosquito transmission $[4,16,17]$ with ZIKV being the first known arbovirus that could be also

(c) The Author(s). 2019 Open Access This article is distributed under the terms of the Creative Commons Attribution 4.0 International License (http://creativecommons.org/licenses/by/4.0/), which permits unrestricted use, distribution, and 
transmitted directly from human-to-human [18-20]. This latter route of transmission may allow for persistence of ZIKV during times of the year that are not favorable for mosquito proliferation.

The emergence of these medically important arboviruses is associated with geographic expansion of their main mosquito vectors, anthropophilic Ae. aegypti [21] and opportunistic, invasive Ae. albopictus [16, 22, 23]. Also, high mutation rates among RNA viruses produce the conditions for adaptive evolution to new mosquito species and often gains a high degree of receptivity and infectivity which may facilitate disease emergence. As an example, prior to the emergence of the Indian Ocean strain of CHIKV, Ae. aegypti was regarded as the primary epidemic vector with Ae. albopictus being secondary in importance. The Indian Ocean strain of CHIKV acquired a single mutation in the envelope protein gene E1 (A226V) that greatly enhanced the vector competence of Ae. albopictus [24]. This illustrates that CHIKV adapts locally to vectors, which allows for the possibility of establishing enzootic transmission cycles in new regions. Lastly, human movement and has allowed for enhanced contact rates between infected and uninfected hosts and mosquito vectors. It is this latter mechanism which may have allowed for the emergence of the Asian lineage of CHIKV in the Americas.

The above provides a clear explanation why DENV, $\mathrm{CHIKV}$, and ZIKV co-circulate in the same geographic area infested with competent mosquito vectors, Ae. aegypti and Ae. albopictus. In this context, cases of patients' co-infection at least by two viruses (ZIKV/CHIKV or DENV/CHIKV) are reported [25-27], where co-infection occurs via single or multiple mosquito bites [28, 29].

In the absence of specific antiviral drugs and vaccines and in context of given viruses co-circulation and similarity, sensitive diagnostic tools for their detection and discrimination are in great demand.

RT-PCR is regarded as the gold standard for pathogen detection because of its specificity and lower rates of false negatives compared to alternative approaches for arbovirus surveillance such as RAMP (Rapid Analytical Measurement Platform) and the Genie II (OptiGene Co.) [30, 31].

Here we present a PCR amplification-based multiplexed Luminex Direct Hybridization Assays (DHAs) diagnostics panel that discriminates DENV1-4, CHIKV, and ZIKV with a low limit of detection of 20 (DENV1) or 80 (ZIKV, DENV2), or 10 (DENV3-4, CHIKV) genome equivalents per assay. Although molecular assays based on PCR-amplification and target-specific hybridization are considered more accurate and sensitive than serological or biological tests, multiplexing often decrease assay resolution [32] and primers dimers usually generate false positives. These obstacles are resolved by a series of innovations from the field of synthetic biology (SAMRS and AEGIS nucleotides), reported previously [32, 33] and shown in Fig. 1 (adapted from [32]) that allowed the elimination of PCR "noise" and increased hybridization efficiency on Luminex microspheres. The assays panel was validated first with all six types of viral RNA (purified from infected Vero cells) and after DENV, ZIKV and CHIKV were detected in a single infected mosquito, in mosquito pools or mosquito saliva (CHIKV and DENV2). DENV2-4 RNA detection was evaluated on the background of nucleic acids from pooled mosquitoes. Infected mosquitoes and saliva were also positively assessed on the surface of a cationic $(\mathrm{Q})$-paper $[34,35]$ that bound mosquito and viral nucleic acids via electrostatic interactions.

The multiplexed diagnostics panel presented here combined with a Q-paper capture surface has the potential for a much wider range of applications than only mosquito surveillance, such as the evaluation of clinical samples (serum, urine, whole blood, and amniotic fluid).

\section{Methods \\ Viral strains \\ Oligonucleotides used in this study}

Primers and probes (Table 2 and Additional file 1: Table S1) were designed using the "in house" StrainTargeter software package. This procedure was described in our previous publication [32]. PCR-primers built from SAMRS and Luminex probes containing AEGIS nucleotides (Table 2) were synthesized on ABI 394 and ABI 3900 using AEGIS and SAMRS phosphoramides (www.firebirdbio.com). Standard oligonucleotides were purchased from Integrated DNA Technology (IDT, Coralville, USA).

\section{Mosquito collections and rearing}

Laboratory colonies of Ae. aegypti from collections in Florida were used in the ZIKV, CHIKV, and DENV1-4 infection studies. Larvae were reared at an approximate density of 150 larvae/L water in plastic trays $(25 \mathrm{~cm} \times 30$ $\mathrm{cm} \times 5 \mathrm{~cm})$ with water $(900 \mathrm{~mL})$ and larval food $(0.4 \mathrm{~g})$ consisting of equal amounts of brewer's yeast and liver powder (by weight) at hatching, and supplemented again with the same amount of food 3-4 days later. Mosquitoes were maintained as described in [34] and allowed to feed on chickens at the Florida Medical Entomology Laboratory once per week to propagate eggs (IACUC protocol no. 201507682). Ae. aegypti females laid eggs on damp paper towels in water filled cups. The progeny of these mosquitoes were used for arbovirus infection studies in the biosafety level-3 virology facility at the Florida Medical Entomology Laboratory in Vero Beach, FL.

\section{Propagation of arboviruses}

Isolates of emergent strains of arboviruses (Table 1) were provided by the Centers for Disease Control and Prevention (ZIKV, CHIKV, DENV1-4, MVEV, CEV, LACV, JEV, YFV, MAYV), Florida Department of Health (DENV1), 


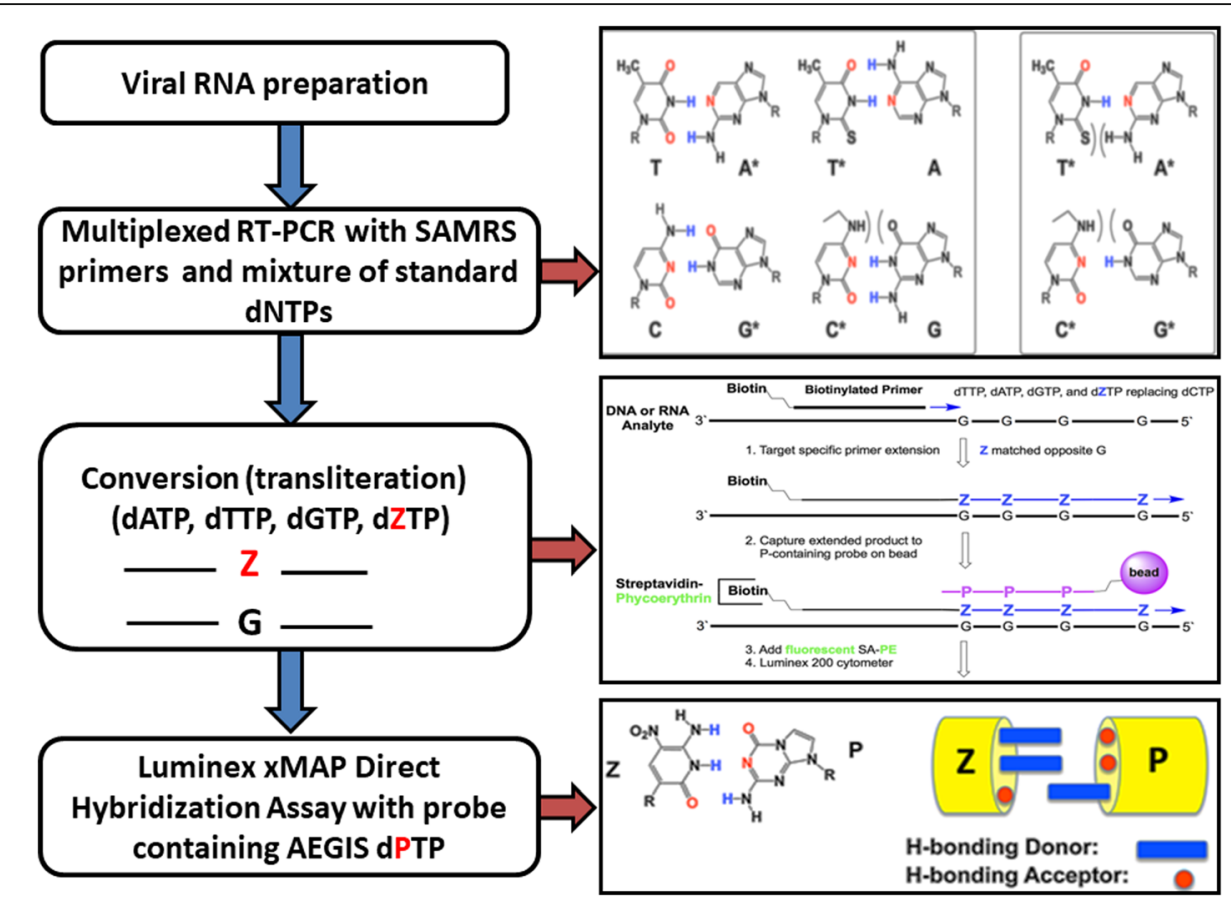

Fig. 1 Adapted from [32, 34]. Left panels: Overview of the Luminex XMAP DHAs protocol developed to detect DENV, CHIKV, and ZIKV RNAs. Right top panel: The strategic removal of hydrogen bonding groups gives a self-avoiding molecular recognition system, SAMRS. Right middle panel: The "transliteration" strategy allows a template G to direct the incorporation of the AEGIS base Z by primer extension, which exploits the mismatch between $\mathrm{G}$ and deprotonated Z. Right bottom panel: The artificially expanded genetic information system (AEGIS) adds up to eight nucleotides and contributes four additional base pairs to the four standard nucleotides by strategically rearranging hydrogen bonding patterns. The AEGIS Z: $P$ pair is exploited in this work

Table 1 Arboviruses in this study and their viral titer

\begin{tabular}{|c|c|c|}
\hline Family/Genus & Viruses /strains/GenBank & $\begin{array}{l}\text { Viral stocks titers, genome } \\
\text { equivalents } / \mathrm{mL}\end{array}$ \\
\hline \multirow[t]{8}{*}{ Flaviviridae/ Flavivirus Group IV positive ssRNA } & DENV1 from Key West (2010), BOL-KW010; GB: JQ675358 & $1.9 \times 10^{8}$ \\
\hline & DENV2, New Guinea C (1944), M29898WSV & $2 \times 10^{6}$ \\
\hline & DNV3, H-87, (1956), TC00881 WSV & $1.6 \times 10^{7}$ \\
\hline & DENV4, H-87, (1956), TC00881 WSV & $4 \times 10^{8}$ \\
\hline & ZIKV, Puerto Rico (2015), strain H/PF/2013; GB: KU501215.1 & $1.12 \times 10^{10}$ \\
\hline & JEV, Nakayama-GIII (1935) GB: EF531853.1 & $1 \times 10^{10}$ \\
\hline & YFV, Ghana/Asibi/1927 GB: AY640589 & $4.57 \times 10^{9}$ \\
\hline & MVEV, MVE-1-51, GB: AF161266 & $2.69 \times 10^{7}$ \\
\hline \multirow[t]{3}{*}{ Togaviridae/Alphavirus Group IV, positive ssRNA } & $\begin{array}{l}\text { CHIKV, La Reunion (2006), Indian Ocean strain (IOC), LR2006- } \\
\text { OPY1, GB: KT449801 }\end{array}$ & $1.89 \times 10^{8}$ \\
\hline & $\begin{array}{l}\text { CHIKV, British Virgin Islands (2013), BVl, Asian lineage; GB: } \\
\text { KJ451624 }\end{array}$ & $2.4 \times 10^{10}$ \\
\hline & MAYV, strain TRVL 4675 (1954) GB: MK070492.1 & $3.8 \times 10^{7}$ \\
\hline \multirow[t]{2}{*}{$\begin{array}{l}\text { Peribunyaviridae/ Orthobunyavirus Group V } \\
\text { negative ssRNA }\end{array}$} & $\begin{array}{l}\text { CEV, BFS283, } \\
\text { Small segment (S), GB: U12797) Medium segment (M), GB: } \\
\text { AF123483 }\end{array}$ & $2.69 \times 10^{10}$ \\
\hline & $\begin{array}{l}\text { LACV, Original Wisconsin virus (LACV/ human/1960) GB: } \\
\text { EF485030-EF485032 }\end{array}$ & $4.37 \times 10^{9}$ \\
\hline
\end{tabular}


and the University of Texas Medical Branch in Galveston, TX (CHIKV).

All arboviruses were obtained from human clinical samples of patients residing in or having traveled to geographic regions during outbreaks (Table 1). We created virus stocks by propagating isolates in cultured African green monkey (Vero) cells as described in [35]. Viral titer was determined by plaque assay using procedures similar to established techniques [36-38]. Propagation of ZIKV, CHIKV, and DENV1-4 for infectious blood meals was accomplished by inoculating confluent monolayers of Vero cells in tissue culture flasks $\left(175 \mathrm{~cm}^{2}\right)$ with diluted stock. Following a 1-h incubation period at $37^{\circ} \mathrm{C}$ with a $5 \%$ carbon dioxide atmosphere, media $(25 \mathrm{~mL})$ was added to each T-175 $\mathrm{cm}^{2}$ flask with cells. Media from cell cultures were harvested following an incubation period (CHIKV, 2-days; ZIKV, DENV1-4, 7-days).

\section{Dengue, chikungunya, and Zika infected mosquitoes}

Cohorts of 50 adult female mosquitoes aged 10-12 days old were placed in cylindrical cages (height $\mathrm{x}$ diameter: $10 \mathrm{~cm}$ by $10 \mathrm{~cm}$ ) with mesh lids and allowed to feed for 1 hour on arbovirus-infected blood from an artificial feeding system (Hemotek, Lancashire, United Kingdom) with hog casing membranes. Mosquitoes were deprived of sucrose $24 \mathrm{~h}$ before feeding trials. Infectious blood meals consisted of defibrinated bovine blood (Hemostat Laboratories, Dixon, CA) and media from infected cell cultures. Adenosine triphosphate $(0.005 \mathrm{M})$ was added to the infected blood as a phagostimulant [39]. Following feeding trials, mosquitoes were anesthetized at $4{ }^{\circ} \mathrm{C}$ and sorted based on observed meal sizes [40]. Fully engorged females were retained and kept at $30^{\circ} \mathrm{C}$ and a photoperiod of 14:10 light:dark hours for a length of time that approximated the extrinsic incubation period (ZIKV, 14 days (Zimler and Alto, unpublished data); CHIKV, $6 \mathrm{~d}$ [40]; and DENV1-4, 14 days [41]. The extrinsic incubation period is the time from acquisition of the pathogen (ingestion) until the time when transmission (by bite) is possible, measured in days. Adults were provided with $10 \%$ sucrose solution from cotton pads. After specified incubation periods, females were tested for transmission potential by the presence of virus in its saliva [41] or individually stored in $2.0 \mathrm{~mL}$ centrifuge tubes at $-80^{\circ} \mathrm{C}$ until tested for virus infection. Mosquitoes were dissected to separate the bodies from the legs, which were tested separately as indicators of susceptibility to infection and disseminated infection.

\section{Saliva from chikungunya infected mosquitoes}

Seven days after ingestion of DENV-2 and CHIKV-infected blood, females were individually transferred to $37-\mathrm{mL}$ plastic tubes and saliva was collected as described in [35]. The chosen time to collect saliva was based on maximizing the amount of expectorated viruses in saliva [41-43]. The honey was dyed with blue food coloring to provide a visual marker indicating that mosquitoes ingested honey and expectorated saliva onto the Q-paper [41, 44]. Mosquitoes were examined as described in [35] for blue in their crop after $24 \mathrm{~h}$. Mosquitoes and Q-paper were stored at $-80^{\circ} \mathrm{C}$, and Q-paper was tested for the presence of DENV2 or CHIKV RNA for mosquitoes that fed on blue honey.

\section{Nucleic acid isolation from arboviral stocks and mosquito tissues}

Bodies and legs of individual mosquitoes were homogenized separately and viral RNA was isolated as described in [34, 35]. Quantitative RT-PCR for the presence of arboviral RNA was determined as in [35], using the Superscript III One-Step qRT-PCR with Platinum ${ }^{\circ}$ Taq kit (Invitrogen, Carlsbad, CA) with the CFX96 Real-time PCR Detection System (Bio-Rad Laboratories, Hercules, CA). Primers and probe sets synthesized by IDT (Integrated DNA Technologies, Coralville, IA) had the following sequences:

\section{ZIKV [35]:}

Forward Primer, 5' - CTTCTTATCCACAGCC GTCTC-3'

Reverse Primer, 5' - CCAGGCTTCAACGTCG TTAT-3'

Probe, $5^{\prime}$-156-FAM/AGAAGGAGACGAGATGCGG TACAGG/3BHQ_1/-3'

The program for qRT-PCR consisted of a 30-min step at $50{ }^{\circ} \mathrm{C}$ linked to a 40 -cycle PCR $\left(94{ }^{\circ} \mathrm{C}\right.$ for $12 \mathrm{~s}$ and $58^{\circ} \mathrm{C}$ for $60 \mathrm{~s}$ ).

CHIKV [34]:

Forward Primer, 5'-GTACGGAAGGTAAACTGGT ATGG-3'

Reverse Primer, 5' -TCCACCTCCCACTCCTTAAT-3' Probe, 5' -/56-FAM/TGCAGAACCCACCGAAAG GAAACT/3BHQ_1/-3'

The RT-PCR assay consisted of a 30-min RT step at $50^{\circ} \mathrm{C}$ linked to a 40 -cycle PCR $\left(94^{\circ} \mathrm{C}\right.$ for $10 \mathrm{~s}$ and $60^{\circ} \mathrm{C}$ for $60 \mathrm{~s})$.

DENV:

Forward Primer, 5'-GACACCACACCCTTTGG ACAA-3'

Reverse Primer, 5'-CACCTGGCTGTCACCTCCAT-3' Probe, 5'-/56-FAM/AGAGGGTGTTTAAAG

AGAAAGTTGACACGCG/3BHQ_1/-3'

The RT-PCR assay consisted of a 30-min RT step at $60^{\circ} \mathrm{C}$ linked to a 40 -cycle PCR $\left(95^{\circ} \mathrm{C}\right.$ for $15 \mathrm{~s}$ and $60^{\circ} \mathrm{C}$ for $60 \mathrm{~s}$ ). Viral stocks were treated similarly, but without homogenization. 
Presence of arboviral RNA in the legs of mosquitoes indicate a disseminated infection, a prerequisite for transmission potential [45]. Bodies of mosquitoes with disseminated infection were squished onto the Q-paper and aqueous ammonia $(50 \mu \mathrm{L} 1 \mathrm{M})$ was added on to the carcass, and adsorbed through the Q-paper and allowed to dry at $22-24{ }^{\circ} \mathrm{C}$ for $20 \mathrm{~min}$ and then frozen at $-80^{\circ} \mathrm{C}$. Mosquito saliva samples were prepared similarly on Q-paper. Mosquito samples and saliva were shipped to Firebird Biomolecular Sciences, LLC for further arbovirus testing as described below.

\section{Preparation of cationic paper (Q-paper) and measuring its} binding capacity

Q-paper was produced by a modification of a procedure from [46]. Its binding capacity was estimated using 1, 3, 5 -benzenetricarboxylic acid. Both protocols were presented previously [34, 35].

\section{Conventional reverse transcription (RT) PCR}

RT-PCR was performed with purified viral RNA or infected mosquito total nucleic acids (NA) using SuperScript One-Step RT-PCR with Platinum Taq (Thermo Fisher Scientific, Carlsbad, CA). Each reaction was set up accordingly to the manufacturer's protocol. Typically, Forward or Reverse primers were added in the reaction mixture to a final concentration of $0.3 \mu \mathrm{M}$. To optimize the reaction, additional $\mathrm{MgSO}_{4}(1.5 \mathrm{mM})$ was added to the RT-PCR mixture, increasing the final magnesium concentration to $2.7 \mathrm{mM}$. Cycling conditions from [35] were optimized for a six-fold multiplexed PCR-format: one cycle of the cDNA synthesis and pre-denaturation $\left(53^{\circ} \mathrm{C}\right.$ for $30 \mathrm{~min}$ and $94^{\circ} \mathrm{C}$ for $2 \mathrm{~min}$ ), 35 cycles of PCR $\left(94{ }^{\circ} \mathrm{C}\right.$ for $15 \mathrm{~s}, 54^{\circ} \mathrm{C}$ for $30 \mathrm{~s}$, and $70^{\circ} \mathrm{C}$ for $30 \mathrm{~s}$ ) and final extension at $72{ }^{\circ} \mathrm{C}$ for $5 \mathrm{~min}$.

\section{Transliteration}

Reverse primer extension reaction (RPER) [32, 47] was performed with each PCR-amplicon to aid incorporation of $5^{\prime}$-biotinylated reverse primers and convert dCTPs into dZTPs in the resulting amplicon ("transliteration") as described in [34].

The RT-PCR or RPER were incubated in DNA Engine ${ }^{\circ}$ Multi-Bay Thermal Cyclers (BioRad, Hercules, CA, USA) or in miniPCR ${ }^{\circ}$ Thermal Cycler (Carolina Biological Supply Company, Burlington, NC). The latter is a small, portable unit that can be used in the field. Its PCR software downloads to any smart device (as smart phones) running operating systems such as Macintosh ${ }^{\circ} \mathrm{OS}$, Windows ${ }^{\circ}$, or Android $^{\mathrm{m}}$. The program also allows the user to monitor and to analyze the process in real time.

\section{Luminex direct hybridization assay (DHA)}

The dPTP-containing capture probes with an amino-C12 linker at their $5^{\prime}$-ends were coupled to Luminex MicroPlex carboxylated microspheres (Luminex, Austin TX) as described in [32,34]. Beads were suspended in Tris-EDTA ( $\mathrm{pH} 8.0$ ) to a final volume of $100 \mu \mathrm{L}$ and counted with a light microscope.

Luminex direct hybridization assays (DHAs) [48] were performed using a "no wash" protocol as described previously [32,34] with a few modifications. Briefly, aliquots $(5 \mu \mathrm{L})$ of each RPER (section 2.10) were transferred to 96-well plates (PCR thermo polystyrene; Costar Technologies, Coppell TX). Microspheres were briefly vortexed and sonicated for $20 \mathrm{~s}$, and 2500 of each microsphere types coupled to the target-specific probes were added to the $2 \mathrm{X}$ hybridization buffer $(25 \mu \mathrm{L}$ of $2 \mathrm{X}$ Tm buffer; $0.4 \mathrm{M} \mathrm{NaCl}$; $0.2 \mathrm{M}$ Tris; 0.16 Triton X-100, pH 8.0). The total volume was adjusted to $50 \mu \mathrm{L}$ with $20 \mu \mathrm{L}$ sample buffer (10 mM Tris, 05.mM EDTA, pH 8.0). Sample buffer $(25 \mu \mathrm{L})$ was then added to each background well (negative control). Hybridization was performed at $57^{\circ} \mathrm{C}$ followed by the Luminex DHA protocol: $95^{\circ} \mathrm{C}$ for $5 \mathrm{~min}$, cool to $57^{\circ} \mathrm{C}$ at a speed of $0.1{ }^{\circ} \mathrm{C} /$ second, $15 \mathrm{~min}$ at the hybridization $\mathrm{T} 57^{\circ} \mathrm{C}$. Hybridization buffer $(25 \mu \mathrm{L}$ of $1 \mathrm{XTm})$ containing streptavidin-R-phycoerythrin at final concentration of $0.3 \%$ (PJRS14, PROzyme, Hayward CA) was added to each hybridization mixture and incubated at $57^{\circ} \mathrm{C}$ for $15 \mathrm{~min}$. Each hybridization reaction was triplicated, and "no-target" controls were run in replicates of five. All assays were analyzed for internal bead color and R-phycoerythrin reporter fluorescence using a Luminex 200 analyzer (Luminex xMAP Technology) and the xPonent Software solutions. The median reporter fluorescence intensity (MFI) was computed for each microsphere type in the sample (six totals). The instrument's gate setting was established before the samples were run and maintained throughout the course of the study.

\section{Results}

Development of six-fold multiplexed RT-PCR based Luminex DHA platform for detection of four dengue serotypes, chikungunya, and Zika viruses and validation of panel sensitivity

Viral RNA stock solutions were purified from viral isolates propagated in Vero cell culture, tittered, and expressed as genome equivalents.

Several sets of primers and probes were designed to target each viral RNA (Additional file 1: Table S1). First, all standard primers and probes were tested by monoplexed conventional RT-PCR followed by a downstream hybridization on the Luminex platform. Next, six-fold multiplexed assays were assembled and performed with viral RNAs and combinations of primers/probes that improved assay performance (data not shown). Finally, the 
oligonucleotides that contributed to assay sensitivity (the lowest detection limit) and specificity (didn't cross react with any other viruses of the assay panel) were selected and their counterparts containing SAMRS and AEGIS nucleotides were synthesized (Table 2) and tested with DENV1-4, CHIKV, and ZIKV RNAs. For this, one-step RT-PCRs $(20 \mu \mathrm{L}$ each) were performed with $1 \mu \mathrm{L}$ of viral RNA (each RNA input is shown in Table 3). An aliquot of each of the double-stranded amplicons $(2.5 \mu \mathrm{L}$ of each PCR) were transferred into the reverse-primer extension/ transliteration reaction $(20 \mu \mathrm{L})$ to favor the production of single-stranded biotinylated amplicons containing the AEGIS base dZTP. The final products were hybridized, on a liquid Luminex platform, against six types of Luminex beads, each annealed to target-specific probes containing the complementary AEGIS base dPTP (Fig. 1). Beads were analyzed for specific fluorescence (median fluorescence intensity, MFI), generated by the R-phycoerythrin reporter. Fluorescence was produced only by double-stranded amplicon-probe hybrids bound to beads of known identities. All assays (6 repeats for each RNA tested) were positive and specific, generating a strong and clear fluorescence signal (MFI), while a "no template" negative control remained at background level (Fig. 2).

To validate the sensitivity of the diagnostics panel (the level of RNA detection), each viral RNA stock was diluted serially (10-fold steps) and each of the dilutions was evaluated by the panel for the presence of each specific viral RNA (Fig. 3). For this, $1 \mu \mathrm{L}$ of each RNA dilution was transferred to the six-fold multiplexed RT-PCR, followed by a "transliteration" reaction and, finally, by downstream detection on the six-fold multiplexed Luminex platform. Aliquots from ten independent dilutions were analyzed. The limits of assay detection (LOD) were 10 genome equivalents for DENV3-4, 20 genome equivalents for DENV1, and 80 genome equivalents for ZIKV or DENV2. Next, the diagnostics panel were validated on infected mosquito samples.

\section{Evaluation of dengue, chikungunya, and Zika viruses in single infected mosquito and mosquito pools with one infected mosquito by a multiplexed diagnostics panel}

To confirm the infection, viral titers in leg tissue were evaluated by plaque assays.

Total nucleic acids (NA) were purified from $A e$. aegypti or Ae. albopictus mosquito bodies found to be virus-positive (Table 4) and control mosquitoes (non-infected, $n=50)$. An aliquot $(1-3 \mu \mathrm{L})$ from each NA preparation $(50 \mu \mathrm{L})$ was used for specific viral RNA detection. Totally, 50 infected mosquitoes (confirmed by leg titration) were analyzed for each virus tested.

All assays were positive for the appropriate pathogen and generated only strong specific fluorescent signals (in the 3000- to 8000- MFI -units range) (Fig. 4,

Table 2 PCR primers and Luminex probes in this study. All reverse primers are 5'- biotinylated. All probes have 5'-amino-C12modified. P, AEGIS nucleotide; *, SAMRS nucleotides. R, mixed A, and G bases. Position of primers and probes refer to the chosen sequence of the viral strains

\begin{tabular}{|c|c|c|c|c|}
\hline Oligonucleotide identity & Oligonucleotides sequences & Position, nucleotides bases & GB accession number & Targeting gene/ region \\
\hline DENV1 Forward primer & GGCCRGATTAAGCC ${ }^{*} A^{*} T^{*} A^{*} G$ & $10,267-10,349$ & KY926849.1 & UTR \\
\hline DENV1 Probe & APAPCTATPCTPCCTPT & & & \\
\hline DENV1 Reverse primer & GCTTTCGGCCTGA*C**T*T*C & & & \\
\hline DENV2 Forward primer & CGTGTCRACTGTRCA* $A^{*} C^{*} A^{*} G$ & $17-136$ & KY461768.1 & Capsid/pre-membrane protein gene \\
\hline DENV2 Probe & АТTСТСАСТTPPAATPСТPC & & & \\
\hline DENV2 Reverse primer & ARTATCCCTGCTGTT* $G^{*} G^{*} T^{*} G$ & & & \\
\hline DENV3 Forward primer & AACACTCTGGGAAGGAT* $\mathrm{C}^{*} \mathrm{~A}^{*} \mathrm{C}^{*} \mathrm{C}$ & $7405-7507$ & KT726361.1 & Non-structural Protein NS4B \\
\hline DENV3 Probe & TТPPAACACCACPATAPCT & & & \\
\hline DENV3 Reverse primer & AGCAAGCCCAGCT ${ }^{*} C^{*} C^{*} T^{*} G$ & & & \\
\hline DENV4 Forward primer & GCAGGCAAAAGCCA* $C^{*} A^{*} A^{*} G$ & $3289-3430$ & AH0119363.2 & Non-structural protein NS2A \\
\hline DENV4 Probe & APTPPACPPPATAACAPT & & & \\
\hline DENV4 Reverse primer & CATGACCTGCCCTA*A*T*T*G & & & \\
\hline CHIKV Forward primer & CAGATGGCAACGAA* $C^{*} A^{*} G^{*} G$ & $6083-6273$ & KY575571.1 & Non-structural protein nsP4 \\
\hline CHIKV FS-1 Probe & ССТTTPCAAPCTCCAPATC & & & \\
\hline CHIKV Reverse primer & GGGTCCTCTGAGCT* $T^{*} \mathrm{C}^{*} \mathrm{~T}^{*} \mathrm{C}$ & & & \\
\hline ZIKV Forward primer & AGGGACCTCCGACT* $G^{*} A^{*} T^{*} G$ & $9981-10,112$ & KY415991.1 & Non-structural protein NS5 \\
\hline ZIKV Probe & PAAAPPPAPAATPPATPACC & & & \\
\hline ZIKV Reverse primer & CCTCAATCCACACTCT ${ }^{*} \mathrm{G}^{*} \mathrm{~T}^{*} \mathrm{~T}^{*} \mathrm{C}$ & & & \\
\hline
\end{tabular}


Table 3 Viral RNA used in assays (genome equivalents)

\begin{tabular}{llllllll}
\hline Virus & DENV1 & DENV2 & DENV3 & DENV4 & ZIKV & CHIKV, La Reunion & CHIKV, BVI \\
\hline Viral RNA/ $20 \mu$ L assay & $1.9 \times 10^{4}$ & $2 \times 10^{2}$ & $1.6 \times 10^{3}$ & $4 \times 10^{3}$ & $1.89 \times 10^{4}$ & $2.4 \times 10^{5}$ & $1.89 \times 10^{4}$ \\
\hline
\end{tabular}

representative data shown). Two of all samples produced an additional, smaller, non-specific CHIKV signal (as an example, ZIKV-infected Ae. aegypti mosquito \#61 is presented in Fig. 4). Assays performed with non-infected mosquito NA (negative controls) were at background level and displayed similar Luminex profiles (representative assay in Fig. 4).

Next, we assembled pools of $5,10,15,25$ or $50 \mathrm{Ae}$. aegypti mosquitoes, each with only one DENV1-, ZIKV- or CHIKV-infected individual $(\mathrm{P}+)$, and total $\mathrm{NA}$ were purified. Infected mosquitoes were confirmed by mosquito "leg" tittering (data not shown). Pools of 9, 14, 24 and 49 non-infected mosquitos (-P) were analyzed in parallel. In total, 10 pools for each combination were analyzed. All assays performed with NA from infected mosquito pools were positive for the given pathogen, and only virus-specific signals were registered on the Luminex platform (for DENV: 2000 to 2500 MFI units, for CHIKV: 2000 to 4000 and for ZIKV: 4000-6000). All assays with NA from non-infected mosquito pools were at background (Fig. 5, the representative data for each group are shown).

To explore the range of dengue serotypes, DENV24 RNA were analyzed within a NA mosquito background by adding ("spiking") RNA from serotypes 2, 3 , and 4. Here, DENV2-4 RNA (100 genome-equivalent, lesser then the content of a single infected mosquito) was mixed with NA purified from pooled non-infected Ae. aegypti mosquitoes for assay evaluation. The assay was capable to detect each serotype RNA in given pools (Fig. 6, representative data for each group are shown). DENV-4 RNA was analyzed on the NA background of 15 or 50 Ae. aegypti mosquitoes. MFI values obtained in these latest assays were 2000 and 1500 MFI, similar to values registered for DENV-3 RNA. Mosquito background did not interfere with the DENV2-4 RNA; neither false positive signals nor false negative signals were seen.

\section{Evaluation of viral RNA in infected mosquitoes and saliva} on cationic (Q) paper surface by multiplexed diagnostics panel

Previously [34, 35], we presented the simple technology needed to collect, preserve, and analyze an infected mosquito on Q- paper (overview presented in Fig. 7a). First, Ae. aegypti mosquito bodies or saliva infected by CHIKV or ZIKV and non-infected controls were "squashed" on Q-paper and treated with a drop ammonia solution $(\mathrm{pH} \geq 12$, with added $\mathrm{NaOH})$ to disintegrate the mosquito tissue and release viral RNA. Next, the NAs were eluted with $1 \mathrm{M} \mathrm{NaCl}$ solution, and eluates were column-desalted then analyzed by the workflow described above. Each sample infection was confirmed in the same way as mentioned in section above.

With this Q-paper platform, laboratory mosquitoes infected with CHIKV $(n=35)$ and ZIKV $(n=25)$ or saliva from DENV2-infected $(n=30)$ and CHIKV-infected $(n=35)$ mosquitoes were analyzed by (Fig. 7b-c, e (representative data for each group are shown)). All
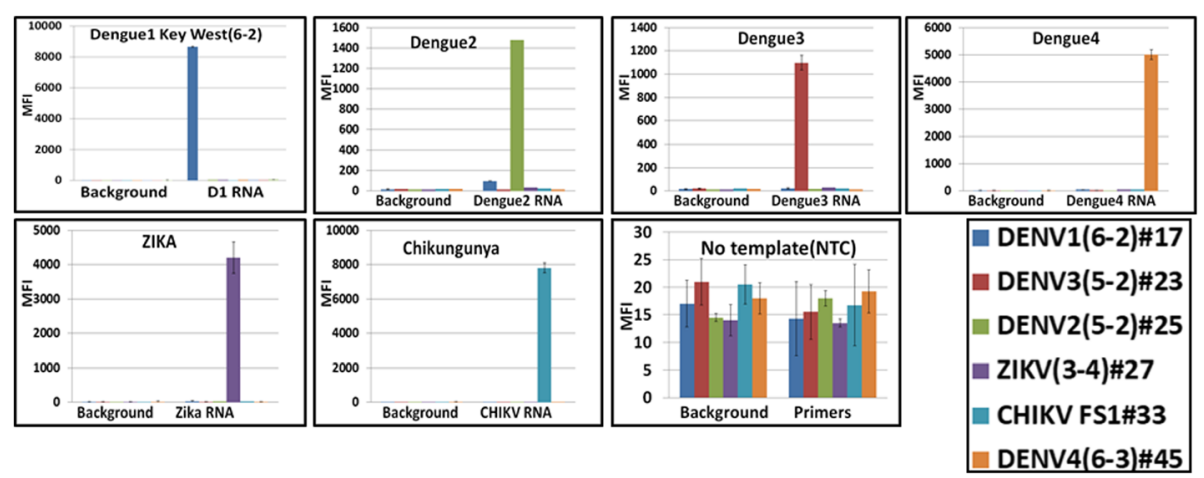

Fig. 2 The six-fold multiplexed XMAP Luminex diagnostics panel for detection of DENV1-4, CHIKV, and ZIKV in mosquitoes was developed using viral RNAs (Table 1). Luminex DHA profiles are presented: each DHA was performed with biotinylated viral PCR-amplicon and six target-specific, dPTP-containing probes. The SAMRS technology was employed for RT-PCR, and AEGIS technology for molecular hybridization on Luminex beads. MFI, median fluorescent intensity (Luminex unit); Background, sample buffer was added to the wells; NTC, no template control, dd $\mathrm{H}_{2} \mathrm{O}$ was added to RT-PCR mixture; lower right panel presents Luminex bead identities. Each bead annealed to a target-specific probe: for example, D1 (6-2) \#17 stands for DENV1 (D1) probe (6-2) annealed to Luminex bead \#17 

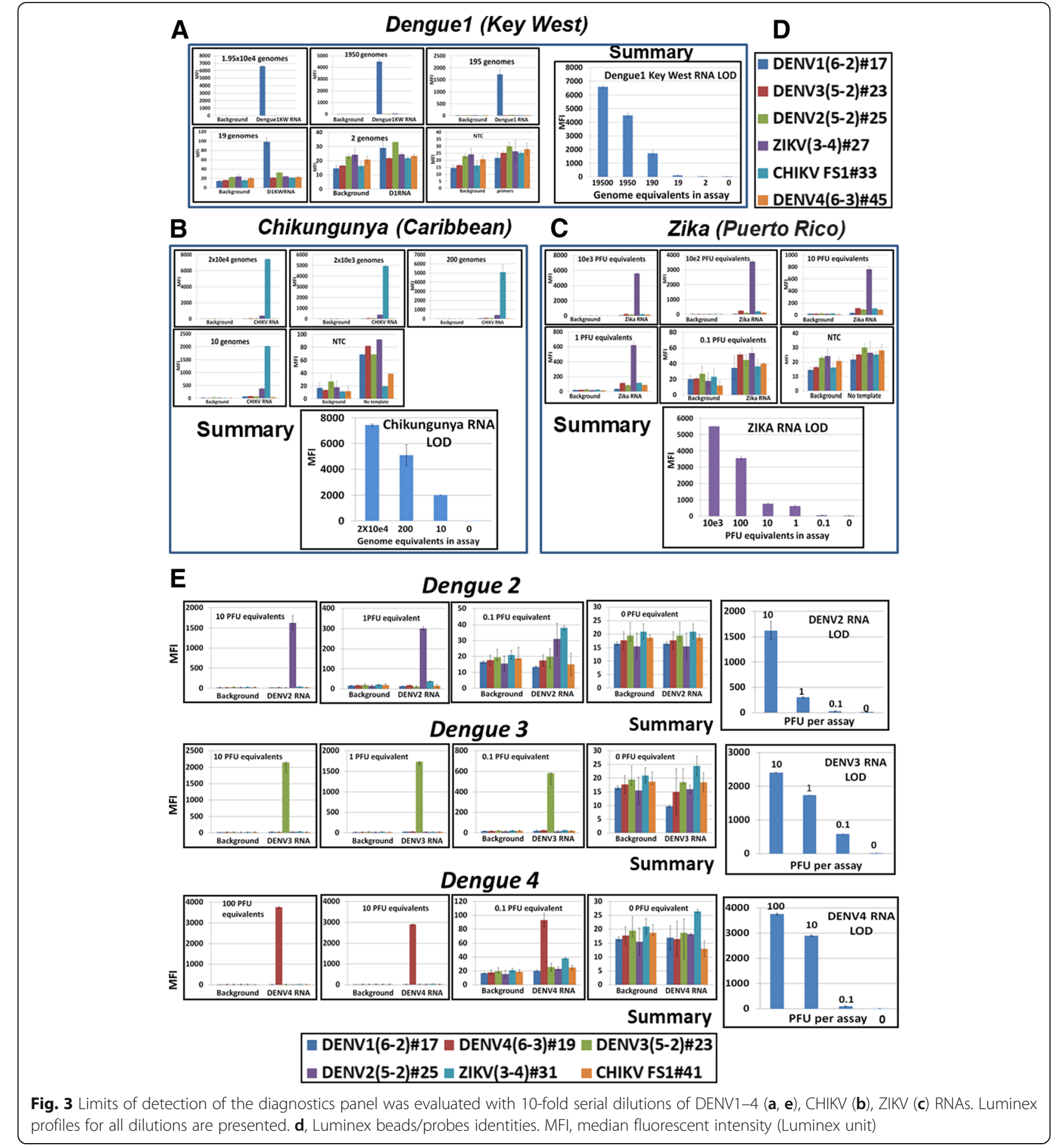

D

multiplexed assays were positive for the appropriate viral RNA and generated only target-specific and clear fluorescent signals. All negative controls were at background level (Fig. 7d, e). Saliva samples generated lower fluorescence, but agreed with DENV2 or CHIKV loads in saliva samples ("leg" titer about $10^{4}$ genomes equivalents $/ \mathrm{mL}$ ) (Fig. 7e). Sensitivity of the assays did not differ among the Asian and Indian Ocean lineages of CHIKV.
Some of the Q-paper samples with Ae. aegypti mosquitoes infected by CHIKV were not eluted, but analyzed directly on Q-paper (Fig. 6f, $n=10$, representative data are shown). For this, Q-paper with infected mosquito was cut and the small fragment $(2 \times 4 \mathrm{~mm})$ was added directly to the RT-PCR mixture and analyzed by the assays panel. The assay with CHIKV-infected mosquito samples produced target-specific signal (about 400 
Table 4 Examples of viral titers in infected mosquito leg tissue

\begin{tabular}{lll}
\hline Virus & Mosquito identity & Leg titer, genome equivalents $/ \mathrm{mL}^{2}$ \\
\hline DENV1 & Ae. aegypti \#168 & $1.18 \times 10^{5}$ \\
DENV1 & Ae. aegypti \#169 & $1 \times 10^{3}$ \\
CHIKV & Ae. albopictus \#11 & $1.81 \times 10^{5}$ \\
CHIKV & Ae. albopictus \#14 & $0.4 \times 10^{3}$ \\
CHIKV & Ae. albopictus \#15 & $1.71 \times 10^{6}$ \\
CHIKV & Ae. albopictus \#16 & $6.67 \times 10^{5}$ \\
CHIKV & Ae. albopictus \#19 & $8.78 \times 10^{5}$ \\
ZIKV & Ae. aegypti \#16 & $4.01 \times 10^{5}$ \\
ZIKV & Ae. aegypti \#19 & $3.99 \times 10^{6}$ \\
ZIKV & Ae. aegypti \#26 & $1.98 \times 10^{6}$ \\
ZIKV & Ae. aegypti \#57 & $7.70 \times 10^{5}$ \\
ZIKV & Ae. aegypti \#61 & $6.10 \times 10^{5}$ \\
\hline A Alower virat is prestin mosquto
\end{tabular}

${ }^{\mathrm{a}} \mathrm{A}$ lower viral titer is present in mosquito legs than in the whole mosquito body, as described for DENV [49] and CHIKV [60, 61]

MFI units). The intensity of fluorescence might correlate with the quantity of RNA on these small Q-paper pieces. Negative control (non-infected Ae. aegypti mosquitoes on similar paper fragments $(n=8))$ slightly exceeded the background level.

\section{Evaluation of non-related arboviruses from Flaviviridae, Peribunyaviridae and Togaviridae families by multiplexed diagnostics panel}

To increase the panel value, additional non-related viruses from Flaviviridae (JEV, YFV, MVEV), Peribunyaviridae (CEV, LACV) and Togaviridae (MAYV) families (Table 1) were evaluated. Ten, 100, and 1000 genomes of each viral RNA were loaded to the reaction mixtures $(n=6$ for each viral RNA concentration). Positive controls were DENV1, CHIKV and ZIKV RNA (100 genomes/assay, $n=3$ for each virus). No template controls were included in each assay group to judge primer dimers.

All non-related viral assays were negative while DENV1, CHIKV and ZIKV generated positive signals (2000 MFI, 4000 MFI and 1000 MFI respectively).

Separately, 100 genome equivalents of each non-related viruses or DENV1, CHIKV, ZIKV (positive controls) were analyzed on mosquitoes background (pool $n=15$, each assay was triplicates). All assays with non-related viruses were negative. All controls were positive (in a range of 1500-3000 MFI).

\section{Discussion}

Given the uncontrolled invasion of DENV, CHIKV, and ZIKV into non-endemic areas, and in the absence of vaccines and specific antiviral drugs, these mosquito-borne viruses are now having great medical importance worldwide $[4,49]$.
Because the diseases generated by these viruses are transmitted by competent mosquitoes, sensitive and comprehensive methods are needed for viral surveillance. Such comprehensive diagnostics assays might be also the primary tools to reduce the risk of outbreaks through arbovirus surveillance of their mosquito vectors, enabling targeted mosquito control in high-risk areas.

Due to high specificity and sensitivity, nucleic acid amplification-based tests (NAATs) are valued for pathogen detection and discrimination. Numerous NAATs capable of detecting ZIKV, CHIKV or DENV have been reported [50-53], but few are commercially available (such as BioRad [54], GESIG [55], Altona diagnostic [56] and etc.).

In this study, a comprehensive multiplexed diagnostics panel for detection of these emerging viral pathogens was developed and validated. The panel is capable to discriminate given arboviruses with a limit as low as 1020 genome equivalents for CHIKV, DENV1, DENV3-4, or up to 80 genome equivalents for DENV2 and ZIKV. The panel backbone is a reverse-transcription PCR amplification followed by the direct hybridization assay on a Luminex platform. To increase sensitivity and performance, artificial nucleotides were used in PCR primers (SAMRS) and Luminex probes (AEGIS). These technologies have been tested and described previously for other targets [32]. In the current study, the introduction of SAMRS primer improved PCR and eliminated non-specific CHIKV signal in DENV1 multiplexed assays with standard primers (data not show).

Next, the diagnostics panel was validated with NA from mosquitoes infected with DENV1-4, CHIKV, and ZIKV or with NA from mosquito pools that included only one infected mosquito. The infected mosquitoes were selected by evaluation of viral titer by qRT-PCR of dissected leg tissue. The multiplexed assays were positive for the appropriate pathogen, and generated strong virus-specific signal when pathogens were pooled with non-infected mosquito samples.

As an additional control group, non-related arboviruses (samples of pure viral RNAs and viral RNAs on mosquito background) from Flaviviridae, Peribunyaviridae and Togaviridae families were evaluated by given panel with only negative outcomes.

We also tested mixed viral RNA, and after combinations of 2-4 mosquitoes infected with either four serotypes of DENV or a single serotype of DENV and ZIKV/ CHIKV. All outcomes were positive. Each virus included in assay generated the specific signal but values of the signals varied (data are not shown in this paper). It would be an extremely rare event for single mosquitoes to become naturally infected by three viruses. Therefore, these types of infected mosquito samples are less important overall contributors to arbovirus epidemiology. 


\section{A \\ Dengue1-infected Ae.aegypti mosquitoes}

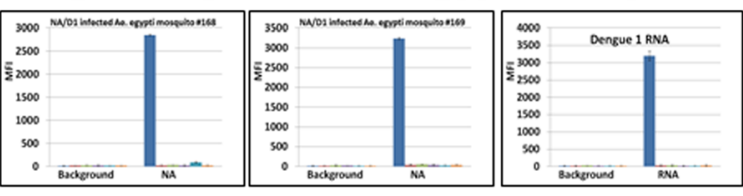

CHIKV-infected Ae.aegypti mosquitoes

\section{Non-infected}
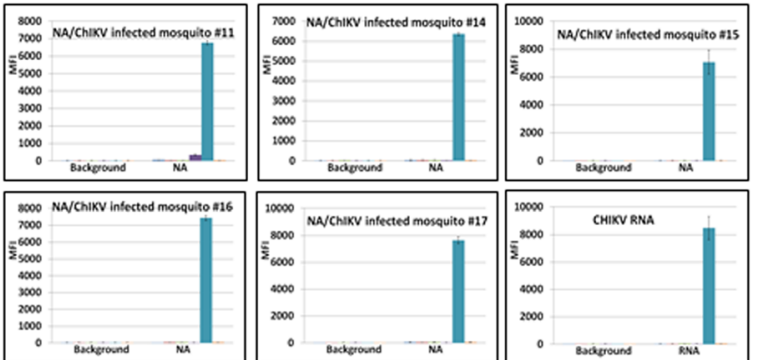

Ae.aegypti mosquito

Zika-infected Ae.aegypti mosquitoes
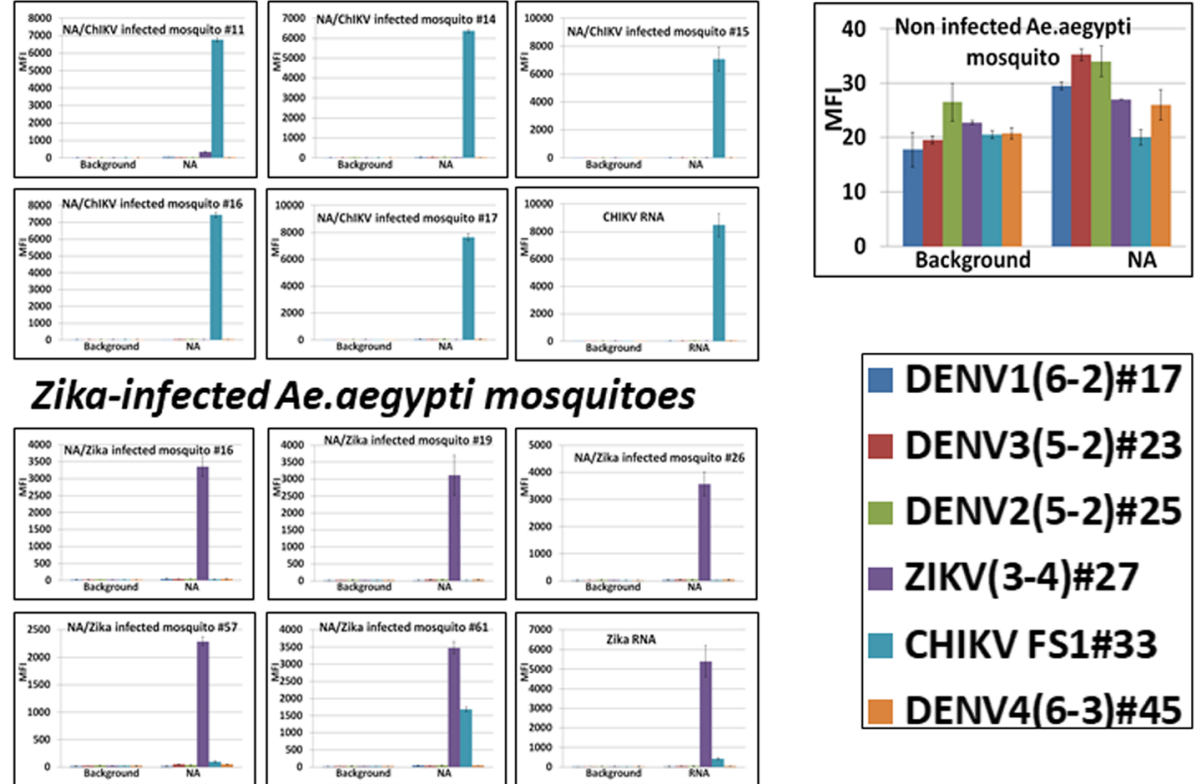

B

Dengue3-infected Ae.aegypti mosquitoes
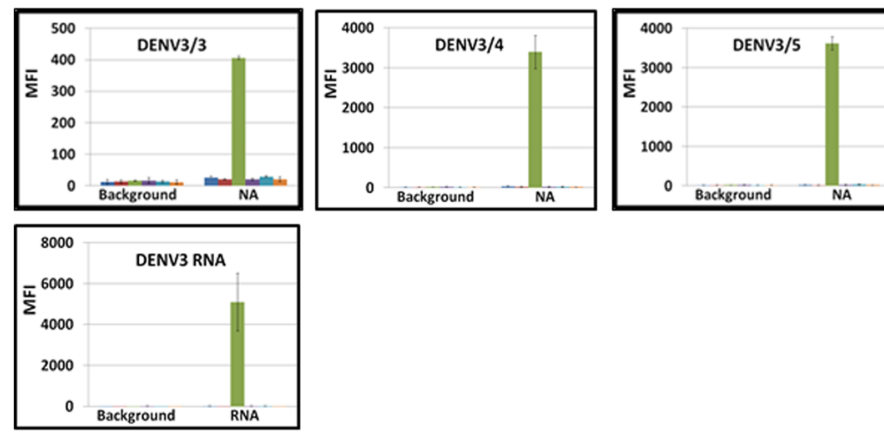

Dengue4-infected Ae.aegypti mosquitoes
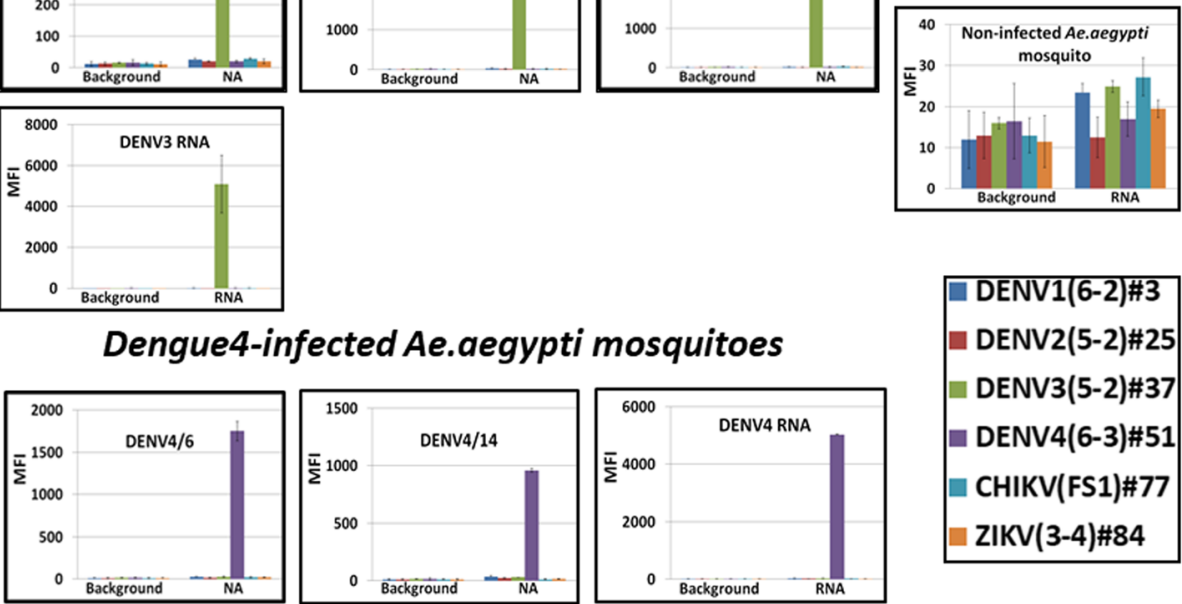

Fig. 4 DENV, CHIKV, and ZIKV were detected in single Ae. aegypti infected mosquitoes. Panels form left present Luminex profiles of six-fold multiplexed DHAs for infected mosquitoes and right top panel presents representative assay for non-infected mosquito (negative control); right bottom panel presents identities of Luminex beads and probes with artificial dPTP 


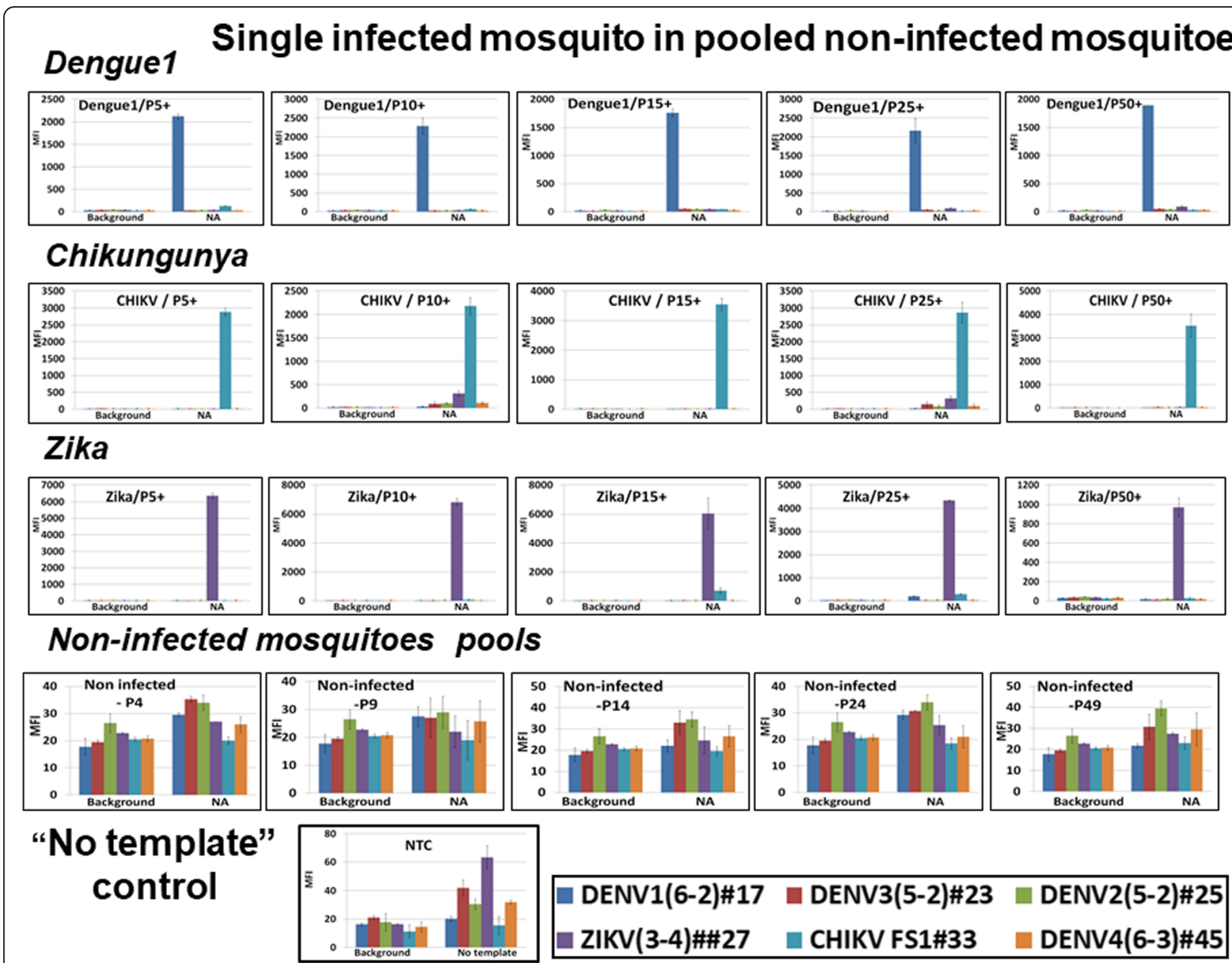

Fig. 5 DENV, CHIKV, and ZIKV were detected in mosquito pools (5-50) containing only one infected individual (three rows of top panels) but not in pools (4-49) of non-infected mosquitoes (negative controls, bottom panel). NTC, "No template" negative control; MFI, median fluorescent intensity

Moreover, although all given viruses could circulate simultaneously in the same area, only one or two would dominate. It is unlikely that a pool of 25 mosquitoes collected for viral surveillance would contain all six viruses together. It is also obvious that if this happened, the given viruses would be reproduced in mosquitoes species non-equally.

Previously [34, 35], a cellulose-based paper ("Q-paper"), derivatized with quaternary ammonium groups was shown to be a convenient platform to collect (in the field or in the laboratory), preserve, and store mosquitoes or mosquito saliva for downstream detection of pathogens (workflow shown in Fig. 7). Here we coupled the Q-paper technology for mosquito bodies and saliva collection with downstream arbovirus detection by the multiplexed diagnostics panel reported. The Q-paper eluates were positive in all infected samples, with strong specific outcomes on the Luminex platform, while non-infected samples showed background level fluorescence (Fig. 7).
Separately, pathogen from infected mosquito bodies on Q-paper was evaluated directly by PCR (Fig. 7f). These also displayed positive results if an arbovirus was present. The approach described above omitted the need for a NA purification step and simplified the assay procedure.

One limitation of the current study is that we did not compare the performance of our assay against currently available multiplex qPCR assays for arbovirus detection (e.g. Genesig, CDC Trioplex, and AccuPower). It is difficult to judge and compare the efficiency of commercial assays without experiments that make use of aliquots from the same biological samples. In general, we can summarize here, that most of the existing assays are monoplexed (as Genesig assays: CHIKV kit based on real time RT-PCR, capable of detecting about 100 copies of targeted template, and RNA extraction is needed). There are a few commercial assay that are multiplexed, allowing for discrimination between DENV, CHIKV, ZIKV, but not among DENV serotypes. An evaluation of 


\section{Spikes of viral RNA on the background of pooled non-infected mosquitoes NA}

\section{Dengue2}
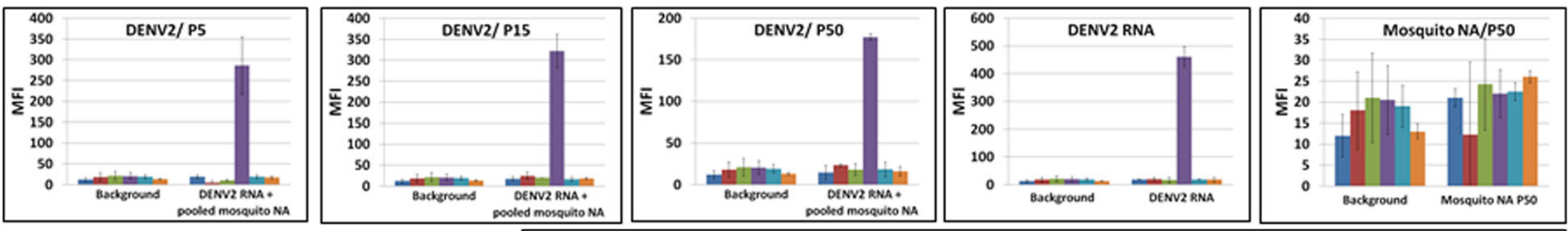

DENV1(6-2)\#17 — DENV4(6-3)\#19 — DENV3(5-2)\#23

Dengue3
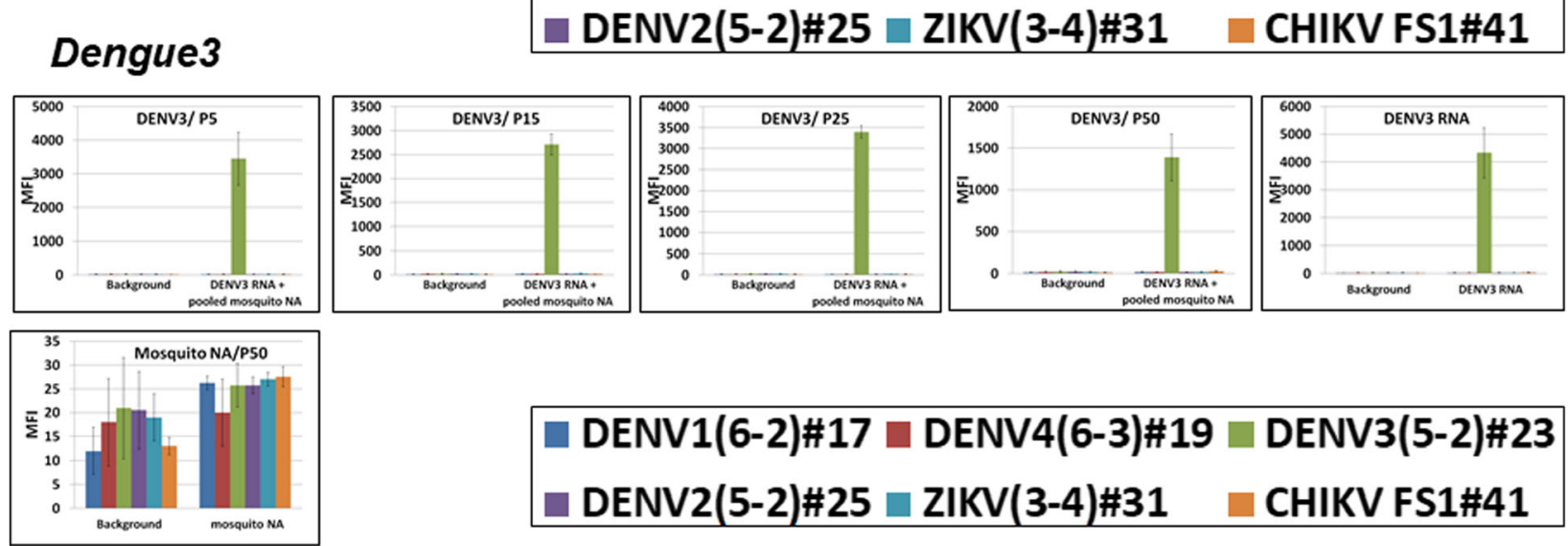

Fig. 6 Validation of DENV2-3 RNA spikes (1 PFU equivalent) on the background of pooled mosquitoes' NA. P5, P15, P25, P50, pools of 5, 15, 25 and 50 Ae. aegypti mosquitoes; MFI, median fluorescent intensity (Luminex unit); panels "DENV2 or 3 RNA", positive assay control, 1PFU of viral RNA was analyzed by multiplexed assay; mosquito NA/50, negative control, mosquito RNA purified from pool of 50 individuals was analyzed by the multiplexed assay

Trioplex real-time RT-PCR (Trioplex assay) in serum, whole blood, and for ZIKV in urine showed a limit of detection of approximately $10^{3}$ genome copy equivalents/mL [57]. A review of 14 molecular assays for ZIKV, all with emergency use authorization as permitted by the U.S. Food and Drug Administration, showed a range of detection from about 12 to $1.9 \times 10^{4}$ copies or genomic copy equivalents $/ \mathrm{mL}$ [58]. Taken together, the current study demonstrates assays that are similar or more sensitive to detection of arboviruses in the multiplex assay. Sensitivity of monoplex and multiplex assays are especially important for ZIKV surveillance given relatively low viral loads in humans $(2.7-3.9 \mathrm{log}$ copies $/ \mathrm{mL}$ in whole blood and 2.2 to $2.8 \log$ copies $/ \mathrm{mL}$ in plasma [58, 59]. Our design and methodology has the benefit of omission of viral RNA purification. Most of the other assays require RNA purification. In the current study, we coupled a Q-paper tool for mosquito sample collection and storage which allows for omission of the RNA purification step followed by downstream viral RNA detection. We demonstrate that our methods are robust for arbovirus sample collection and detection by RT-PCR.
Future work in this area should evaluate how commercially available multiplex qPCR assays for arbovirus detection compare to our assays.

In laboratories equipped with PCR-machine and Luminex instrument, the cost of single assay will not exceeded $\$ 15-20$ (plus labor cost). The assay flow (Fig. 1) includes three steps: reverse-transcription PCR (about $1.5 \mathrm{~h}$ ), transliteration (about $20 \mathrm{~min}$ ) and specific molecular hybridization on Luminex beads $(1 \mathrm{~h}$, depending on the amount of sample). So, skilled technicians should be able to successfully complete the assay in about $3-4 \mathrm{~h}$.

In modern version of Luminex instrument all three assay steps can be consecutively executed on Luminex platform (all reagents are loaded in Luminex cartridge and all three reactions performed automatically without spatial separation, minimizing possible contamination). The 96-plate format of Luminex platform is an obvious advantage of our approach that reduces a cost of a single assay if run separately.

In summary, mosquito samples can be field-collected on Q-paper and transferred to a laboratory equipped with Luminex instrument, store and analyzed in a 


\section{Ae.aegypti infected mosquitoes and saliva on Q-paper}

A
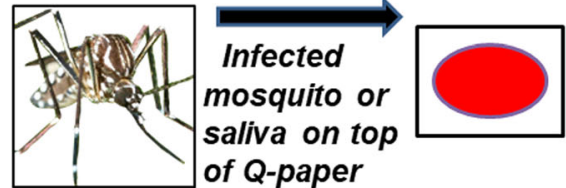

Ammonia treatment

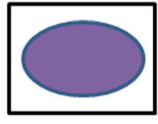

Elution

and of Q-paper

detection

\section{B Zika/mosquito}

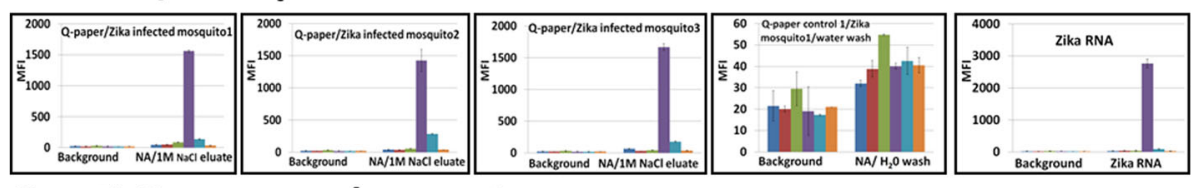

\section{Chikungunya/mosquito}
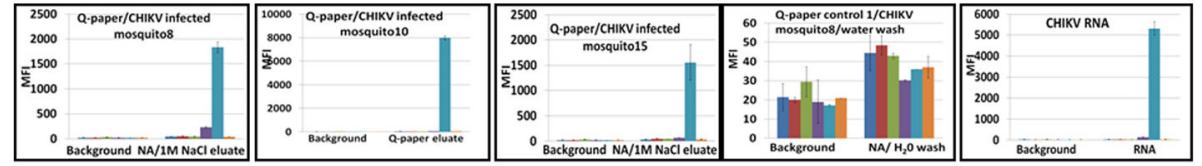

D Non-infected mosquitoes

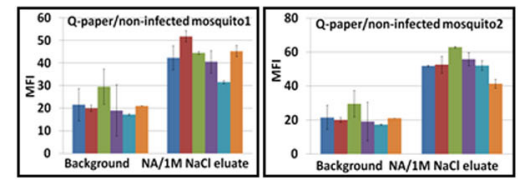

DENV1(6-2)\#17 — DENV3(5-2)\#23 - DENV2(5-2)\#25 $\because \mathrm{ZIKV}(3-4) \# 27$ E CHIKV FS1\#33 DENV4(6-3)\#45

\section{E Chikungunya and DENV2/saliva}

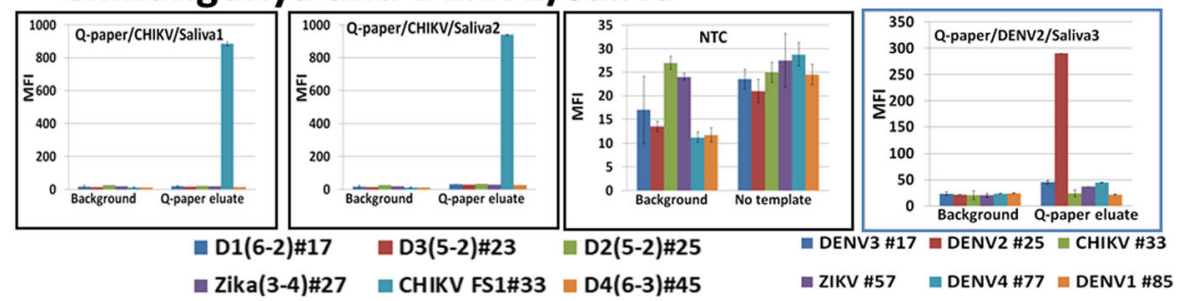

\section{F Q-paper samples were analyzed directly in PCR tubes}
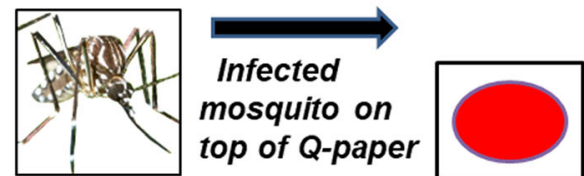

Ammonia treatment
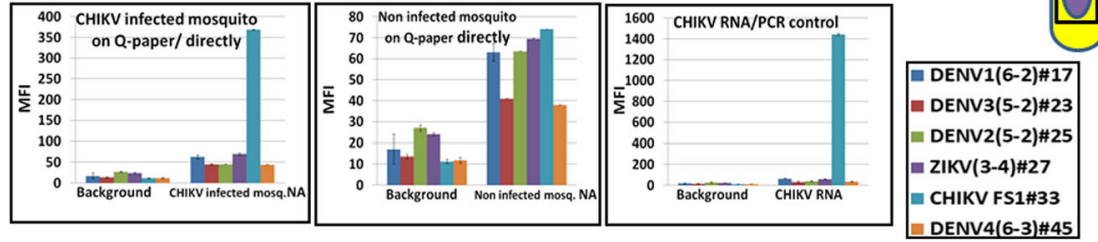

Fig. 7 ZIKV- and CHIKV-infected mosquito detection on cationic (Q) paper. a, sample preparation and procedure overview; b, Luminex profiles of the assays performed with ZIKV-infected mosquitoes and controls; c, Luminex profiles of the assays performed with CHIKV-infected mosquitoes and controls; d, Non-infected mosquitoes on Q-paper, negative controls; e, Saliva from CHIKV and DENV2 infected mosquitoes on Q-paper, two panel on the bottom present Luminex beads and probes pairs; $\mathbf{f}$, infected mosquito on Q-paper analyzed directly by RT-PCR. Negative control, non-infected mosquito on Q-paper validated directly by RT-PCR. NA, total nucleic acids isolated from infected or non-infected mosquito tissues. Right bottom panel presents Luminex beads and probes pairs. Mosquito images by NDBC

statistically sufficient scope by the multiplexed Luminex-based assay. This technology may be a useful tool for mosquito monitoring and surveillance, especially in areas where dengue, chikungunya, and Zika co-circulate.
This methodological tool based on synthetic biology may be used in other applications as well, such as high-throughput detection of pathogens in clinical samples. 


\section{Additional file}

Additional file 1: Table S1. PCR primers and Luminex probes designed for this study. $R$, mixed $A$ and $G$ bases; $Y$, mixed $C$ and $T$ bases.

Oligonucleotides s selected to assemble the diagnostics panel are in Italic Bold. (DOCX $13 \mathrm{~kb})$

\section{Abbreviations}

AEGIS: Artificially expanded genetic information systems; CEV: California encephalitis virus; CHIKV: Chikungunya virus; DENV1-4: Dengue serotypes 14 viruses; IACUC: Institutional Animal Care and Use Committee; JEV: Japanese encephalitis virus; LACV: La Crosse virus; MAYV: Mayaro virus; NS: Nonstructural; Q-paper: Cellulose-based cationic paper; RT-PCR: Reverse transcription polymerase chain reaction; SAMRS: Self-avoiding molecular recognition systems; xMap Luminex technology: Multi-Analyte Profiling Luminex technology; YFV: Yellow fever virus; ZIKV: Zika virus

\section{Acknowledgments}

We thank Bradley Eastmond and Keenan Wiggins for assistance with experiments using arboviruses.

\section{Funding}

Research reported in this publication was supported by the National Institute of Allergy and Infectious Diseases of the National Institutes of Health under Award Number R21Al128188, Florida Department of Health (7ZK15), and the Florida Department of Agriculture and Consumer Services (contract\# 024376). The design of the study, analysis and interpretation of data, and writing the manuscript is solely the responsibility of the authors and does not necessarily represent the official views of the NIH, FDH or FDACS.

\section{Availability of data and materials}

All data generated or analyzed during this study are included in this published article and its additional file. Primers and probes containing artificial nucleotides are available from the corresponding author on reasonable request.

\section{Authors' contributions}

LGG generated the project idea, designed and performed experiments, analyzed data, drafted a manuscript; BWA performed experiments and drafted a manuscript; MSK produced Q-paper; DH synthesized primers and probes with artificial nucleotides; $A B$ helped with Luminex experiments; KMB designed primers and probes; NDBC helped with mosquito infection and drafted a manuscript; SAB generated the project idea and drafted a manuscript. All authors have read and approved the manuscript.

\section{Ethics approval and consent to participate}

Not applicable.

\section{Consent for publication}

Not applicable.

\section{Competing interests}

Several authors of this paper and their institutions own intellectual property associated with the assay, including SAMRS, AEGIS, and the conversion/ capture technologies. Several of the items mentioned here are sold by Firebird Biomolecular Sciences, LLC, which employs the indicated authors and is owned by SAB.

\section{Publisher's Note}

Springer Nature remains neutral with regard to jurisdictional claims in published maps and institutional affiliations.

\section{Author details}

${ }^{1}$ Firebird Biomolecular Sciences LLC, 13709 Progress Blvd, Box 17, Alachua, FL 32615, USA. Florida Medical Entomology Laboratory, University of Florida, 200 9th Street SE, Vero Beach, FL 32962, USA.
Received: 13 March 2018 Accepted: 16 April 2019

Published online: 14 May 2019

\section{References}

1. Bhatt $S$, Gething PW, Brady OJ, Messina JP, Farlow AW, Moyes CL, Drake JM, Brownstein JS, Hoen AG, Sankoh O, et al. The global distribution and burden of dengue. Nature. 2013;496(7446):504-7.

2. Cunha RVD, Trinta KS. Chikungunya virus: clinical aspects and treatment - a review. Mem Inst Oswaldo Cruz. 2017:112(8):523-31.

3. Lazear HM, Diamond MS. Zika virus: new clinical syndromes and its emergence in the Western hemisphere. J Virol. 2016;90(10):4864-75.

4. Suwanmanee S, Luplertlop N. Dengue and Zika viruses: lessons learned from the similarities between these Aedes mosquito-vectored arboviruses. J Microbiol. 2017;55(2):81-9.

5. Nishiura $H$, Matsuyama $R$, Asai Y. Estimating risks of Zika virus associated microcephaly and local transmission using mathematical models. Uirusu. 2016;66(1):79-82.

6. Rezza G. Dengue and chikungunya: long-distance spread and outbreaks in naive areas. Pathog Glob Health. 2014;108(8):349-55.

7. Metsky HC, Matranga CB, Wohl S, Schaffner SF, Freije CA, Winnicki SM, West K, Qu J, Baniecki ML, Gladden-Young A, et al. Zika virus evolution and spread in the Americas. Nature. 2017:546(7658):411-5.

8. Vega-Rua A, Zouache K, Girod R, Failloux AB, Lourenco-de-Oliveira R. High level of vector competence of Aedes aegypti and Aedes albopictus from ten American countries as a crucial factor in the spread of chikungunya virus. J Virol. 2014:88(11):6294-306.

9. Haddow AJ, Williams MC, Woodall JP, Simpson DI, Goma LK. Twelve isolations of Zika virus from Aedes (Stegomyia) africanus (Theobald) taken in and above a Uganda Forest. Bull World Health Organ. 1964;31:57-69.

10. Diallo M, Thonnon J, Traore-Lamizana M, Fontenille D. Vectors of chikungunya virus in Senegal: current data and transmission cycles. Am J Trop Med Hyg. 1999;60(2):281-6.

11. Diallo M, Ba Y, Sall AA, Diop OM, Ndione JA, Mondo M, Girault L, Mathiot C. Amplification of the sylvatic cycle of dengue virus type 2, Senegal, 19992000: entomologic findings and epidemiologic considerations. Emerg Infect Dis. 2003;9(3):362-7.

12. Diallo M, Sall AA, Moncayo AC, Ba Y, Fernandez Z, Ortiz D, Coffey LL, Mathiot C, Tesh RB, Weaver SC. Potential role of sylvatic and domestic African mosquito species in dengue emergence. Am J Trop Med Hyg. 2005; 73(2):445-9.

13. Carrington LB, Simmons CP. Human to mosquito transmission of dengue viruses. Front Immunol. 2014:5:290.

14. Coffey LL, Failloux AB, Weaver SC. Chikungunya virus-vector interactions. Viruses. 2014:6(11):4628-63.

15. Bueno MG, Martinez N, Abdalla L. Duarte dos Santos CN, Chame M: animals in the Zika virus life cycle: what to expect from megadiverse Latin American countries. PLoS Negl Trop Dis. 2016;10(12):e0005073.

16. Paupy C, Delatte H, Bagny L, Corbel V, Fontenille D. Aedes albopictus, an arbovirus vector: from the darkness to the light. Microbes Infect. 2009; 11(14-15):1177-85.

17. Higgs $S$, Vanlandingham D. Chikungunya virus and its mosquito vectors. Vector Borne Zoonotic Dis. 2015;15(4):231-40.

18. Magalhaes T, Foy BD, Marques ETA, Ebel GD, Weger-Lucarelli J. Mosquitoborne and sexual transmission of Zika virus: Recent developments and future directions. Virus Res. 2018:254:1-9.

19. Gao D, Lou Y, He D, Porco TC, Kuang Y, Chowell G, Ruan S. Prevention and control of Zika as a mosquito-borne and sexually transmitted disease: a mathematical modeling analysis. Sci Rep. 2016;6:28070.

20. Maxian O, Neufeld A, Talis EJ, Childs LM, Blackwood JC. Zika virus dynamics: when does sexual transmission matter? Epidemics; 2017.

21. Powell JR, Tabachnick WJ. History of domestication and spread of Aedes aegypti--a review. Mem Inst Oswaldo Cruz. 2013;108(Suppl 1):11-7.

22. Benedict MQ, Levine RS, Hawley WA, Lounibos LP. Spread of the tiger: global risk of invasion by the mosquito Aedes albopictus. Vector Borne Zoonotic Dis. 2007;7(1):76-85.

23. Schaffner F, Bellini R, Petric D, Scholte EJ, Zeller $H$, Rakotoarivony LM. Development of guidelines for the surveillance of invasive mosquitoes in Europe. Parasit Vectors. 2013:6:209.

24. Tsetsarkin KA, Vanlandingham DL, McGee CE, Higgs S. A single mutation in chikungunya virus affects vector specificity and epidemic potential. PLoS Pathog. 2007;3(12):e201. 
25. Dupont-Rouzeyrol M, O'Connor O, Calvez E, Daures M, John M, Grangeon JP, Gourinat AC. Co-infection with Zika and dengue viruses in 2 patients, New Caledonia, 2014. Emerg Infect Dis. 2015;21(2):381-2.

26. Myers RM, Carey DE. Concurrent isolation from patient of two arboviruses, chikungunya and dengue type 2. Science. 1967;157(3794):1307-8.

27. Schilling S, Emmerich P, Gunther S, Schmidt-Chanasit J. Dengue and chikungunya virus co-infection in a German traveller. J Clin Virol. 2009;45(2):163-4.

28. Le Coupanec A, Tchankouo-Nguetcheu S, Roux P, Khun H, Huerre M, Morales-Vargas R, Enguehard M, Lavillette D, Misse D, Choumet V. Coinfection of mosquitoes with chikungunya and dengue viruses reveals modulation of the replication of both viruses in midguts and salivary glands of Aedes aegypti mosquitoes. Int J Mol Sci. 2017;18(8):1708.

29. Goertz GP, Vogels CBF, Geertsema C, Koenraadt CJM, Pijlman GP. Mosquito co-infection with Zika and chikungunya virus allows simultaneous transmission without affecting vector competence of Aedes aegypti. PLoS Negl Trop Dis. 2017;11(6):e0005654

30. Nasci RS, Gottfried KL, Burkhalter KL, Kulasekera VL, Lambert AJ, Lanciotti RS, Hunt AR, Ryan JR. Comparison of vero cell plaque assay, TaqMan reverse transcriptase polymerase chain reaction RNA assay, and VecTest antigen assay for detection of West Nile virus in field-collected mosquitoes. J Am Mosq Control Assoc. 2002;18(4):294-300.

31. Burkhalter KL, Horiuchi K, Biggerstaff BJ, Savage HM, Nasci RS. Evaluation of a rapid analyte measurement platform and real-time reverse-transcriptase polymerase chain reaction assay West Nile virus detection system in mosquito pools. J Am Mosq Control Assoc. 2014;30(1):21-30.

32. Glushakova LG, Bradley A, Bradley KM, Alto BW, Hoshika S, Hutter D, Sharma N, Yang Z, Kim MJ, Benner SA. High-throughput multiplexed XMAP Luminex array panel for detection of twenty two medically important mosquitoborne arboviruses based on innovations in synthetic biology. J Virol Methods. 2015;214:60-74.

33. Glushakova LG, Sharma N, Hoshika S, Bradley AC, Bradley KM, Yang Z, Benner SA. Detecting respiratory viral RNA using expanded genetic alphabets and self-avoiding DNA. Anal Biochem. 2015;489:62-72.

34. Glushakova LG, Alto BW, Kim MS, Bradley A, Yaren O, Benner SA. Detection of chikungunya viral RNA in mosquito bodies on cationic $(\mathrm{Q})$ paper based on innovations in synthetic biology. J Virol Methods. 2017;246:104-11.

35. Glushakova LG, Alto BW, Kim MS, Wiggins K, Eastmond B, Moussatche P, Burkett-Cadena ND, Benner SA. Optimization of cationic (Q)-paper for detection of arboviruses in infected mosquitoes. J Virol Met. 2018;261:71-9.

36. Faye O, Faye O, Diallo D, Diallo M, Weidmann M, Sall AA. Quantitative realtime PCR detection of Zika virus and evaluation with field-caught mosquitoes. Virol J. 2013;10:311.

37. Medina F, Medina JF, Colon C, Vergne E, Santiago GA, Munoz-Jordan JL. Dengue virus: isolation, propagation, quantification, and storage. Curr Protoc Microbiol. 2012; Chapter 15:Unit 15D 12

38. Kaur P, Lee RC, Chu JJ. Infectious viral quantification of chikungunya virusvirus plaque assay. Methods Mol Biol. 2016;1426:93-103.

39. Galun R, Avi-Dor Y, Bar-Zeev M. Feeding response in Aedes aegypti: stimulation by adenosine triphosphate. Science. 1963;142(3600):1674-5.

40. Leisnham PT, Sala LM, Juliano SA. Geographic variation in adult survival and reproductive tactics of the mosquito Aedes albopictus. J Med Entomol. 2008; 45(2):210-21.

41. Alto BW, Wiggins K, Eastmond B, Velez D, Lounibos LP, Lord CC. Transmission risk of two chikungunya lineages by invasive mosquito vectors from Florida and the Dominican Republic. PLoS Negl Trop Dis. 2017;11(7):e0005724.

42. Chan M, Johansson MA. The incubation periods of dengue viruses. PLoS One. 2012;7(11):e50972.

43. Dubrulle M, Mousson L, Moutailler S, Vazeille M, Failloux AB. Chikungunya virus and Aedes mosquitoes: saliva is infectious as soon as two days after oral infection. PLoS One. 2009;4(6):e5895.

44. Burkett-Cadena ND, Gibson J, Lauth M, Stenn T, Acevedo C, Xue RD, McNelly J, Northey E, Hassan HK, Fulcher A, et al. Evaluation of the honey-card technique for detection of transmission of arboviruses in Florida and comparison with sentinel chicken seroconversion. J Med Entomol. 2016:53(6):1449-57.

45. Turell MJ, Gargan TP 2nd, Bailey CL. Replication and dissemination of Rift Valley fever virus in Culex pipiens. Am J Trop Med Hyg. 1984;33(1):176-81.

46. Yang F, Song $X$, Yan L. Preparation of cationic waste paper and its application in poisonous dye removal. Water Sci Technol. 2013;67(11):2560-7.

47. Yang Z, Durante M, Glushakova LG, Sharma N, Leal NA, Bradley KM, Chen F, Benner SA. Conversion strategy using an expanded genetic alphabet to assay nucleic acids. Anal Chem. 2013;85(9):4705-12.
48. Dunbar SA. Applications of Luminex xMAP technology for rapid, highthroughput multiplexed nucleic acid detection. Clin Chim Acta. 2006;363(12):71-82.

49. Christofferson RC. Zika virus emergence and expansion: lessons learned from dengue and chikungunya may not provide all the answers. Am J Trop Med Hyg. 2016;95(1):15-8.

50. Cabral-Castro MJ, Cavalcanti MG, Peralta RHS, Peralta JM. Molecular and serological techniques to detect co-circulation of DENV, ZIKV and CHIKV in suspected dengue-like syndrome patients. J Clin Virol. 2016;82:108-11.

51. Calvo EP, Sanchez-Quete F, Duran S, Sandoval I, Castellanos JE. Easy and inexpensive molecular detection of dengue, chikungunya and zika viruses in febrile patients. Acta Trop. 2016;163:32-7.

52. Simmons M, Myers T, Guevara C, Jungkind D, Williams M, Houng HS. Development and validation of a quantitative, one-step, multiplex, real-time reverse transcriptase PCR assay for detection of dengue and chikungunya viruses. J Clin Microbiol. 2016;54(7):1766-73.

53. Pabbaraju K, Wong S, Gill K, Fonseca K, Tipples GA, Tellier R. Simultaneous detection of Zika, chikungunya and dengue viruses by a multiplex real-time RT-PCR assay. J Clin Virol. 2016;83:66-71.

54. Zika, Dengue, and Chikungunya (ZDC) Real-Time PCR BioRed Assays. http:// www.bio- rad.com/en-uk/product/zika-dengue-chikungunya-zdc-real-timepcr-assays

55. Dengue, Zika and Chikungunya Virus Multiplex kit http://www.genesig.com/ products/9762-dengue-zika-and-chikungunya-virus-multiplex-kit

56. RealStar ${ }^{\oplus}$ Zika Virus RT-PCR Kit. https://www.altona-diagnostics.com/en/ products/reagents-140/reagents/realstar-real-time-pcr-reagents/realstar-zikavirus-rt-pcr-kit-ce.html.

57. Santiago GA, Vázquez J, Courtney S, Matías KY, Andersen LE, Colón C, Butler AE, Roulo R, Bowzard J, Villanueva JM, Muñoz-Jordan JL. Performance of the Trioplex real-time RT-PCR assay for detection of Zika, dengue, and chikungunya viruses. Nat Commun. 2018;9(1):1391.

58. Theel ES, Hata DJ. Diagnostic testing for Zika virus: a postoutbreak update. $J$ Clin Microbiol. 2018;56(4):e01972-17.

59. Mansuy JM, Mengelle C, Pasquier C, Chapuy-Regaud S, Delobel P, MartinBlondel G, Izopet J. Zika virus infection and prolonged viremia in wholeblood specimens. Emerg Infect Dis. 2017;23:863-5.

60. Alto BW, Bettinardi D. Temperature and dengue virus infection in mosquitoes: independent effects on the immature and adult stages. Am J Trop Med Hyg. 2013;88(3):497-505.

61. Richards SL, Anderson SL, Smartt CT. Vector competence of Florida mosquitoes for chikungunya virus. J Vector Ecol. 2010;35(2):439-43.

\section{Ready to submit your research? Choose BMC and benefit from:}

- fast, convenient online submission

- thorough peer review by experienced researchers in your field

- rapid publication on acceptance

- support for research data, including large and complex data types

- gold Open Access which fosters wider collaboration and increased citations

- maximum visibility for your research: over $100 \mathrm{M}$ website views per year

At $\mathrm{BMC}$, research is always in progress.

Learn more biomedcentral.com/submission 